\title{
MENINGKATKAN PRESTASI BELAJAR ARITMATIKA SOSIAL DENGAN PENDEKATAN SAINTIFIK KELAS VII SMP MUHAMMADIYAH 1 SURABAYA
}

\author{
Dia Setianingsih ${ }^{1}$, Chusnal Aini ${ }^{2}$, Febriana Kristanti ${ }^{3}$ \\ Program Studi Pendidikan Matematika, Fakultas Keguruan dan Ilmu Pendidikan \\ Universitas Muhammadiyah Surabaya \\ Dia.Setianingsih@yahoo.com
}

\begin{abstract}
ABSTRAK
Banyak yang beranggapan bahwa matematika adalah pelajaran yang sulit untuk diajarkan dan dipelajari. Salah satu karakteristik matematika adalah mempunyai objek yang bersifat abstrak, inilah yang menyebabkan banyak siswa mengalami kesulitan dalam matematika dan guru masih belum menggunakan model pembelajaran yang menarik sehingga siswa kurang aktif dalam proses pembelajaran. Data yang diperoleh berupa data kuantitatif. Teknik analisis data yang digunakan analisis statistik deskriptif, dengan jenis penelitian berupa penelitian tindakan kelas (PTK). Data yang dianalisis deskriptif adalah : ketuntasan belajar dan aktifitas siswa dengan subyek penelitian adalah siswa kelas VII B SMP Muhammadiyah 1 Surabaya.

Hasil penelitian ini dapat disimpulkan nilai prestasi belajar matematika siswa kelas VII B SMP Muhammadiyah 1 Surabaya dapat ditingkatkan melalui pendekatan saintifik dalam proses pembelajaran. Siklus 1 dengan rata-rata 2,82, meningkat sebesar 25,89\% dari nilai pretest. Siklus 2 meningkat $10,28 \%$ dari siklus 1 dengan rata-rata 3,11. Hal ini menunjukkan bahwa siswa senang terhadap proses pembelajaran menggunakan pendekatan ini.
\end{abstract}

Kata Kunci : Pendekatan Saintifik, Prestasi Belajar, Aritmatika Sosial

\section{PENDAHULUAN}

Pendidikan adalah kunci utama untuk melakukan persiapan-persiapan menghadapi perubahan masyarakat sesuai tuntutan era globalisasi. Dunia pendidikan dituntut untuk menghasilkan sumber daya manusia yang unggul. Karena itu kualitas pendidikan menjadi sorotan utama, baik dari segi fasilitas maupun dari segi pembelajaran. Pembelajaran merupakan suatu proses untuk mencapai tujuan tertentu yang telah direncanakan. Secara khusus, pembelajaran merupakan upaya sadar yang dilakukan oleh guru atau pengajar untuk membantu siswa agar dapat belajar dengan mudah.

Berdasarkan kenyataan yang ada di SMP Muhammadiyah 1 Surabaya khususnya kelas VII, siswa menerima saja pembelajaran matematika disekolah tanpa mempertanyakan untuk apa dan mengapa belajar matematika ini penting. Tak jarang muncul keluhan bahwa matematika hanya membuat pusing siswa dan orang tua karena dianggap sebagai hal yang menakutkan. Yang lebih memberatkan lagi yaitu pelajaran matematika disampaikan dengan model pembelajaran langsung 
yang monoton, guru kurang menggunakan model pembelajaran yang bervariasi. Sedangkan KKM (Kriteria Ketuntasan Minimum) sekolah yang tinggi yaitu nilai 75 atau skor 3. Agar siswa dapat dengan mudah memahami konsep yang diajarkan, sesuai dengan kurikulum 2013 proses pembelajaran akan dilaksanakan dengan pendekatan saintifik.

Pendekatan saintifik merupakan pendekatan di dalam kegiatan pembelajaran yang mengutamakan kreativitas dan temuan-temuan siswa. Pengalaman belajar yang mereka peroleh tidak bersifat hafalan dan sejenisnya. Pengalaman belajar, baik itu yang berupa pengetahuan, keterampilan dan sikap mereka peroleh berdasarkan kesadaran dan kepentingan mereka sendiri.

Materi yang mereka pelajari berbasis fakta atau fenomena tertentu, sesuai dengan KD yang sedang dikembangkan guru. Fakta atau fenomena itu mereka amati, mereka pertanyakan, mereka cari jawabannya sendiri dari berbagai sumber yang relevan, dan bermuara pada sebuah jawaban yang dapat dipertanggung jawabkan secara keilmuan. (Kosasih, 2014:72)

Langkah-langkah pendekatan saintifik menurut Kosasih (2014:73) yaitu:

1. Mengamati

2. Menanya

3. Menalar

4. Mengasosiasikan

5. Membangun atau Mengembangkan Jaringan dan Berkomunikasi

\section{METODE PENELITIAN}

Jenis penelitian ini merupakan Penelitian Tindakan Kelas (PTK). Tahap-tahap pelaksanaan PTK ada 4, yaitu :

1. Perencanaan (planing)

2. Pelaksanaan (acting)

3. Pengamatan (observing)

4. Refleksi (reflecting)

Tempat yang digunakan peneliti untuk melakukan penelitian adalah SMP Muhammadiyah 1 Surabaya pada kelas VII B. Penelitian siklus I dilaksanakan pada 
tanggal 22 - 23 April 2015 dan siklus II dilaksanakan pada tanggal 29 - 30 April 2015 .

Teknik pengumpulan data dalam penelitian ini menggunakan beberapa cara, yaitu: (1) Dokumentasi, yaitu untuk memperoleh daftar nilai ulangan tengah semester genap tahun 2014-2015. (2) Tes, yaitu untuk mengetahui tingkat penguasaan siswa terhadap materi yang diajarkan. Dalam penelitian ini soal yang digunakan berbentuk uraian. Siklus I dan siklus II terdiri dari 5 soal dengan Skor maksimum 4 dan skor minimum. (3) Observasi aktivitas siswa, yaitu untuk mengetahui kegiatan-kegiatan apa saja yang dilakukan siswa pada saat kegiatan pembelajaran berlangsung. Pengamatan aktivitas siswa dilakukan oleh 6 orang.

Teknik analisis data yang digunakan adalah teknik deskriptif komparatif yaitu membandingkan keberhasilan antara siklus yang satu dengan siklus berikutnya. Penelitian ini juga menggunakan teknik analisis data kuantitatif, yaitu untuk menggambarkan kenyataan atau fakta sesuai dengan data yang diperoleh dengan tujuan untuk mengetahui hasil belajar yang dicapai siswa.

1. Analisis Data Ketuntasan Hasil Belajar Siswa

Siswa dikatakan tuntas secara individual bila mendapatkan skor $\geq 3$. Dan ketuntasan secara klasikal dicapai jika terdapat $\geq 80 \%$ telah tuntas pada kelas tersebut.

Ketuntasan hasil belajar individual tercapai apabila:

$$
\text { Nilai }=\frac{\text { nilai yang diperoleh }}{\text { jumlah nilai maksimal }} \times 4
$$

Persentase ketercapaian hasil belajar klasikal tercapai apabila :

Persentase ketercapaian $=\frac{\text { banyak siswa yang tuntas }}{\text { banyak siswa seluruhnya }} \times 100 \% \geq 80 \%$

2. Analisis Data Aktivitas Siswa selama Pembelajaran dengan Pendekatan saintifik

Adapun kriteria aktivitas belajar siswa adalah:

a. Memperhatikan/mendengarkan penjelasan guru/teman

b. Bertanya kepada guru jika ada kesulitan

c. Membaca buku paket/LKS

d. Berdiskusi dengan antar teman/guru

e. Menyampaikan pendapat 
f. Mengerjakan LKS

g. Mempresentasikan hasil kelompok

h. Perilaku tidak relevan dengan KBM

Dengan presentase aktivitas siswa sebagai berikut:

$A k=\frac{n\left(A_{i}\right)}{n\left(A_{T o t}\right)} \times 100 \%$

Keterangan: $\mathrm{Ak}=$ Prosentase aktivitas siswa

$$
\begin{aligned}
n\left(A_{i}\right) & =\text { Jumlah aktivitas ke-i yang muncul } \\
n\left(A_{\text {Tot }}\right) & =\text { Jumlah aktivitas keseluruhan }
\end{aligned}
$$

Presentase tersebut dikonversikan dengan kriteria yang diadopsi dari Khabibah (2006) sebagai berikut :

Tabel 2.1

Kategori Aktivitas Siswa

\begin{tabular}{|c|l|}
\hline Persentase Aktivitas Siswa (A) & \multicolumn{1}{|c|}{ Kategori } \\
\hline $90 \% \leq A \leq 100 \%$ & Sangat Aktif \\
\hline $80 \% \leq A<90 \%$ & Aktif \\
\hline $70 \% \leq A<80 \%$ & Kurang Aktif \\
\hline $0 \% \leq A<70 \%$ & Tidak Aktif \\
\hline
\end{tabular}

Pada lembar pengamatan aktivitas siswa terdapat tujuh kategori aktivitas siswa yang relevan dengan KBM dan satu aktivitas yang tidak relevan dengan KBM. Aktivitas siswa memenuhi ketuntasan jika total rata-rata persentase aktivitas siswa selama tiga kali pertemuan yang relevan dengan KBM mencapai kategori aktif atau sangat aktif.

\section{HASIL PENELITIAN DAN PEMBAHASAN}

Pada metode penelitian telah dijelaskan bahwa penelitian ini adalah penelitian tindakan kelas (PTK). Setelah dilakukan penelitian diperoleh data hasil pengamatan terhadap siswa, data sebelum tindakan dan data setelah tindakan. Data sebelum tindakan diperoleh dari hasil pretest dan data sesudah tindakan kelas diperoleh dari hasil tes yang diberikan oleh peneliti setelah menggunakan pendekatan saintifik pada materi aritmatika sosial. 


\section{Siklus I}

Data nilai awal siswa diperoleh dari nilai pretest siswa kelas VII-B SMP Muhammadiyah 1 Surabaya, dan nilai tes siklus I diperoleh dari proses pembelajaran sesuai RPP 1 dan RPP 2 dengan pendekatan saintifik. Data nilai pretest dan nilai siklus I ditunjukkan pada Tabel 3.1.

Tabel 3.1

Rekapitulasi Nilai Matematika Sebelum Penelitian dan Siklus I

\begin{tabular}{|c|c|c|c|c|c|}
\hline & $\mathrm{N}$ & $\begin{array}{c}\text { Tuntas Belajar } \\
(\text { skor } \geq 3)\end{array}$ & $\begin{array}{c}\text { Tidak Tuntas } \\
\text { Belajar } \\
(\text { skor }<3)\end{array}$ & Rata-rata & $\begin{array}{c}\text { Meningkat } \\
(\%)\end{array}$ \\
\cline { 1 - 4 } Nilai Pretest & 36 & $\begin{array}{c}11 \text { siswa } \\
(30,56 \%)\end{array}$ & $\begin{array}{c}25 \text { siswa } \\
(69,44 \%)\end{array}$ & 2,24 & \multirow{2}{*}{2,89} \\
\cline { 1 - 4 } Nilai Siklus 1 & 36 & $\begin{array}{c}22 \text { siswa } \\
(61,11 \%)\end{array}$ & $\begin{array}{c}14 \text { siswa } \\
(38,89 \%)\end{array}$ & 2,82 \\
\hline
\end{tabular}

Dari tabel diatas jika dibandingkan data sebelum tindakan, maka hasil Siklus I mengalami peningkatan hasil belajar pada siswa kelas VII B. Rata-rata nilai hasil belajar siswa dari sebelum tindakan adalah 2,24 dan setelah dilakukan tindakan pada siklus I adalah 2,82. Karena banyaknya siswa yang tuntas pada siklus I belum mencapai minimal $80 \%$ serta nilai rata-rata belum mencapai 3 maka dilanjutkan siklus II.

Data aktivitas siswa menurut kriteria aktivitas siswa yang telah ditetapkan, diperoleh hasil pengamatan seperti yang disajikan pada Tabel 3.2 di bawah ini:

\begin{tabular}{|c|c|c|c|c|c|c|}
\hline \multirow[b]{2}{*}{ No } & \multirow{2}{*}{$\begin{array}{l}\text { Pendekatan } \\
\text { Saintifik }\end{array}$} & \multirow[b]{2}{*}{ Perilaku Siswa } & \multicolumn{3}{|c|}{ Siklus 1} & \multirow{2}{*}{$\begin{array}{l}\text { Persentase } \\
\text { (dalam \%) }\end{array}$} \\
\hline & & & $\begin{array}{c}\text { Pert } \\
1\end{array}$ & $\begin{array}{c}\text { Pert } \\
2 \\
\end{array}$ & $\begin{array}{c}\text { Rata- } \\
\text { rata }\end{array}$ & \\
\hline 1 & Mengamati & $\begin{array}{l}\text { Memperhatikan/menden } \\
\text { garkan penjelasan guru } \\
\text { atau teman }\end{array}$ & 126 & 74 & 100 & 23,15 \\
\hline 2 & Menanya & $\begin{array}{l}\text { Bertanya kepada guru } \\
\text { jika ada kesulitan }\end{array}$ & 113 & 30 & 71,5 & 16,55 \\
\hline 3 & & $\begin{array}{l}\text { Membaca buku } \\
\text { paket/LKS }\end{array}$ & 169 & 49 & 109 & 25,23 \\
\hline 4 & Mengasosiasikan & $\begin{array}{l}\text { Berdiskusi antar teman } \\
\text { atau guru }\end{array}$ & 68 & 33 & 50,5 & 11,69 \\
\hline 5 & & Menyampaikan pendapat & 17 & 16 & 16,5 & 3,82 \\
\hline 6 & Mengeksplorasi & Mengerjakan LKS & 45 & 68 & 56,5 & 13,08 \\
\hline
\end{tabular}


Dia Setianingsih', Chusnal Aini' ${ }^{2}$, Febriana Kristanti ${ }^{3}$

\begin{tabular}{|c|c|c|c|c|c|c|}
\hline \multirow{2}{*}{ No } & \multirow{2}{*}{$\begin{array}{c}\text { Pendekatan } \\
\text { Saintifik }\end{array}$} & Perilaku Siswa & \multicolumn{3}{|c|}{ Siklus 1 } & Persentase \\
\cline { 3 - 7 } & & $\begin{array}{c}\text { Pert } \\
\mathbf{1}\end{array}$ & $\begin{array}{c}\text { Pert } \\
\mathbf{2}\end{array}$ & $\begin{array}{c}\text { Rata- } \\
\text { rata }\end{array}$ & $\begin{array}{l}\text { Mempresentasikan hasil } \\
\text { diskusi kelompok }\end{array}$ \\
\hline 7 & Mengkomunikasikan & 38 & 17 & 27,5 & 6,36 \\
\hline 8 & & $\begin{array}{l}\text { Perilaku yang tidak } \\
\text { relevan dengan KBM }\end{array}$ & 0 & 0 & 0 & 0 \\
\hline \multicolumn{2}{|c|}{ Total } & $\mathbf{5 7 6}$ & $\mathbf{2 8 8}$ & $\mathbf{4 3 2}$ & $\mathbf{1 0 0}$ \\
\hline
\end{tabular}

Dari hasil observasi diperoleh aktivitas siswa yang paling sering dilakukan adalah sebanyak $25,23 \%$ siswa membaca buku paket atau LKS saat pembelajaran berlangsung. Dalam pembelajaran pendekatan saintifik guru lebih aktif memberikan intruksi kepada siswa. Selain mendengarkan intruksi, siswa juga membaca buku paket atau LKS saat pembelajaran berlangsung. Sehingga aktivitas tersebut memiliki persentase yang paling sering dilakukan.

\section{Siklus II}

Berdasarkan hasil refleksi pada siklus I yang belum mencapai indikator keberhasilan maka peneliti melakukan perencanaan pada siklus II agar pembelajaran lebih efektif dan indikator keberhasilan dapat tercapai. Data nilai siklus I dan nilai siklus II jika dibandingkan diperoleh data ditunjukkan pada Tabel 3.3 .

Tabel 3.3

Rekapitulasi Nilai Matematika Siklus I dan Siklus II

\begin{tabular}{|c|c|c|c|c|c|}
\hline & $\mathrm{N}$ & $\begin{array}{c}\text { Tuntas Belajar } \\
(\text { skor } \geq 3)\end{array}$ & $\begin{array}{c}\text { Tidak Tuntas } \\
\text { Belajar } \\
(\text { skor }<3)\end{array}$ & Rata-rata & $\begin{array}{c}\text { Meningkat } \\
(\%)\end{array}$ \\
\hline Nilai Siklus I & 36 & $\begin{array}{c}22 \text { siswa } \\
(61,11 \%)\end{array}$ & $\begin{array}{c}14 \text { siswa } \\
(38,89 \%)\end{array}$ & 2,82 & 10,28 \\
\hline Nilai Siklus II & 36 & $\begin{array}{c}30 \text { siswa } \\
(83,33 \%)\end{array}$ & $\begin{array}{c}6 \text { siswa } \\
(16,67 \%)\end{array}$ & 3,11 & \\
\hline
\end{tabular}

Dari tabel diatas jika dibandingkan data siklus I, maka hasil siklus II mengalami peningkatan hasil belajar pada siswa kelas VII-B. Rata-rata peningkatan hasil belajar siswa setelah dilakukan tindakan pada siklus I adalah 2,82 dan setelah dilakukan tindakan pada siklus II adalah 3,11. Karena nilai ketuntasan mencapai $\geq$ 
3 dan banyaknya siswa yang tuntas pada siklus II mencapai minimal $80 \%$ maka indikator keberhasilan pada siklus II telah tercapai.

Data aktivitas siswa menurut kriteria aktivitas siswa yang telah ditetapkan, diperoleh hasil pengamatan seperti yang disajikan pada Tabel 3.4 di bawah ini:

\begin{tabular}{|c|c|l|c|c|}
\hline No. & $\begin{array}{c}\text { Pendekatan } \\
\text { Saintifik }\end{array}$ & \multicolumn{1}{|c|}{ Perilaku Siswa } & Siklus 2 & $\begin{array}{c}\text { Persentase } \\
\text { (dalam \%) }\end{array}$ \\
\cline { 3 - 4 } & Mengamati & $\begin{array}{l}\text { Memperhatikan/mendengarkan } \\
\text { penjelasan guru atau teman }\end{array}$ & 125 & 21,7 \\
\hline 2. & Menanya & $\begin{array}{l}\text { Bertanya kepada guru jika ada } \\
\text { kesulitan }\end{array}$ & 115 & 19,97 \\
\hline 3. & & Membaca buku paket/LKS & 171 & 29,69 \\
\hline 4. & Mengasosiasikan & Berdiskusi antar teman atau guru & 62 & 10,76 \\
\hline 5. & & Menyampaikan pendapat & 21 & 3,65 \\
\hline 6. & Mengeksplorasi & Mengerjakan LKS & 39 & 6,77 \\
\hline 7. & Mengkomunikasikan & $\begin{array}{l}\text { Mempresentasikan hasil diskusi } \\
\text { kelompok }\end{array}$ & 43 & 7,47 \\
\hline 8. & & $\begin{array}{l}\text { Perilaku yang tidak relevan } \\
\text { dengan KBM }\end{array}$ & 0 & 0 \\
\hline & Total & $\mathbf{5 7 6}$ & $\mathbf{1 0 0}$ \\
\hline
\end{tabular}

Dari hasil observasi diperoleh aktivitas siswa yang paling dominan adalah membaca buku paket atau LKS saat pembelajaran berlangsung memiliki rata-rata sebesar 29,69\%. Dalam pembelajaran pendekatan saintifik guru lebih aktif memberikan intruksi kepada siswa. Selain mendengarkan intruksi, siswa juga membaca buku paket atau LKS saat pembelajaran berlangsung. Sehingga aktivitas tersebut memiliki persentase yang paling sering dilakukan. Aktivitas tersebut cukup baik yang menunjukkan bahwa siswa sudah cukup mampu memahami masalah yang ada pada LKS. Perilaku siswa yang tidak relevan saat pebelajaran pendekatan saintifik dengan rata-rata $0 \%$. Aktivitas tersebut dapat memberikan dampak positif terhadap siswa terhadap berlangsungnya pembelajaran yang diterapkan oleh guru.

\section{SIMPULAN}

Berdasarkan hasil dan pembahasan diatas, maka dapat disimpulkan sebagai berikut:

1. Hasil belajar matematika siswa kelas VII-B SMP Muhammadiyah 1 Surabaya dapat meningkat melalui penerapan pendekatan saintifik. Hal ini dapat dilihat dari hasil nilai pretest ke siklus I yang memperoleh rata-rata 2,82 dan nilai ratarata meningkat sebesar $25,89 \%$. Dan dari nilai siklus I ke siklus II yang 
memperoleh rata-rata 3,11 dan nilai rata-rata meningkat sebesar $10,28 \%$. Dengan demikian penerapan pendekatan saintifik dapat meningkatkan hasil belajar matematika siswa kelas VII-B SMP Muhammadiyah 1 Surabaya.

2. Aktivitas siswa kelas VII-B SMP Muhammadiyah 1 Surabaya setelah penerapan pendekatan saintifik baik siklus I dan siklus II tergolong sangat aktif. Hasil ini ditunjukkan dengan semua aktivitas siswa yang diharapkan dapat terlaksana dengan baik.

\section{DAFTAR PUSTAKA}

Khabibah, Siti. 2006. Pengembangan Model Pembelajaran Matematika dengan Soal Terbuka Untuk Meningkatkan Kreativitas Siswa Sekolah Dasar. Tidak dipublikasikan. Surabaya: PPs Unesa.

Kosasih. 2014. Strategi Belajar dan Pembelajaran (Implementasi Kurikulum 2013). Bandung: Yrama Widya. 